\title{
Tau Protein Is Required for Amyloid $\beta$-Induced Impairment of Hippocampal Long-Term Potentiation
}

\author{
Olivia A. Shipton, ${ }^{1 *}$ Julie R. Leitz, ${ }^{1 *}$ Jenny Dworzak, ${ }^{1}$ Christine E. J. Acton, ${ }^{1}$ Elizabeth M. Tunbridge, ${ }^{2}$ Franziska Denk, ${ }^{1}$ \\ Hana N. Dawson, ${ }^{3}$ Michael P. Vitek, ${ }^{3}$ Richard Wade-Martins, ${ }^{1,4}$ Ole Paulsen, ${ }^{1,5}$ and Mariana Vargas-Caballero ${ }^{1}$ \\ ${ }^{1}$ Department of Physiology, Anatomy, and Genetics, University of Oxford, Oxford OX1 3PT, United Kingdom, ${ }^{2}$ Department of Psychiatry, Warneford \\ Hospital, Oxford, OX3 7JX, United Kingdom, ${ }^{3}$ Division of Neurology, Duke University, Durham, North Carolina 27710, ${ }^{4}$ Oxford Parkinson's Disease Centre, \\ Department of Physiology, Anatomy, and Genetics, University of Oxford, Oxford OX1 3QX, United Kingdom, and 5Physiological Laboratory, Department of \\ Physiology, Development, and Neuroscience, University of Cambridge, Cambridge CB2 3EG, United Kingdom
}

Amyloid $\beta(\mathrm{A} \beta)$ and tau protein are both implicated in memory impairment, mild cognitive impairment (MCI), and early Alzheimer's disease $(\mathrm{AD})$, but whether and how they interact is unknown. Consequently, we asked whether tau protein is required for the robust phenomenon of $\mathrm{A} \beta$-induced impairment of hippocampal long-term potentiation (LTP), a widely accepted cellular model of memory. We used wild-type mice and mice with a genetic knock-out of tau protein and recorded field potentials in an acute slice preparation. We demonstrate that the absence of tau protein prevents $\mathrm{A} \beta$-induced impairment of LTP. Moreover, we show that A $\beta$ increases tau phosphorylation and that a specific inhibitor of the tau kinase glycogen synthase kinase 3 blocks the increased tau phosphorylation induced by $\mathrm{A} \beta$ and prevents $\mathrm{A} \beta$-induced impairment of LTP in wild-type mice. Together, these findings show that tau protein is required for $\mathrm{A} \beta$ to impair synaptic plasticity in the hippocampus and suggest that the $A \beta$-induced impairment of LTP is mediated by tau phosphorylation. We conclude that preventing the interaction between $\mathrm{A} \beta$ and tau could be a promising strategy for treating cognitive impairment in $\mathrm{MCI}$ and early $\mathrm{AD}$.

\section{Introduction}

Amyloid $\beta(\mathrm{A} \beta)$ and tau protein both have well established roles in Alzheimer's disease (AD), forming the two hallmark pathologies visible in postmortem $\mathrm{AD}$ brains as amyloid plaques and neurofibrillary tangles (NFTs), respectively (Hardy and Selkoe, 2002; Small and Duff, 2008). A $\beta$ plays a central role in disease pathogenesis, being implicated in the synaptic dysfunction that is considered a major cellular mechanism underlying the cognitive deficits in patients with mild cognitive impairment (MCI) and early AD (Selkoe, 2002). Plaque formation is preceded by elevated levels of soluble, low- $N$ oligomers of $\mathrm{A} \beta$, and evidence suggests it is these that are responsible for synaptic dysfunction (Lue et al., 1999; Hardy and Selkoe, 2002). Acute exposure to synthetic or naturally secreted $\mathrm{A} \beta$ has been shown to impair hip-

\footnotetext{
Received May 22, 2010; revised 0ct. 27, 2010; accepted Nov. 16, 2010.

This work was supported by the Wellcome Trust and an equipment grant from the Alzheimer's Research Trust (funded by Doris Field Charitable Trust). 0.A.S. holds a Wellcome Trust OXION studentship. E.M.T. is a Royal Society Research Fellow. F.D. held a Wellcome Trust Studentship in Neuroscience. R.W.-M. held a Wellcome Trust Research Career Development Fellowship, and the work was supported in part by CurePSP. M.V.-C. holds a Wellcome Trust OXION Training Fellowship. 0.A.S., J.R.L., J.D., C.E.J.A., E.M.T. and M.V.-C. conducted experiments; H.N.D, M.P.V. and F.D. generated and maintained the $\mathrm{Tau}^{-1-}$ mouse strain; 0.A.S., J.R.L. and M.V.-C. analyzed the data. R.W.-M., O.P. and M.V.-C. designed the experiments. O.A.S., O.P. and M.V.-C. wrote the manuscript. All authors discussed the project and approved the final version of the manuscript.

${ }^{*} 0$. A.S. and J.R.L. contributed equally to this work.

This article is freely available online through the J Neurosci Open Choice option.

Correspondence should be addressed to either of the following: Dr. Mariana Vargas-Caballero, Department of Physiology, Anatomy, and Genetics, University of Oxford, Oxford 0X1 3PT, United Kingdom, E-mail: mariana.vargas@dpag.ox.ac.uk; or Prof. Ole Paulsen, Physiological Laboratory, Department of Physiology, Development, and Neuroscience, University of Cambridge, Cambridge CB2 3EG, United Kingdom, E-mail: op210@cam.ac.uk.

D0I:10.1523/JNEUROSCI.2610-10.2011

Copyright $\odot 2011$ the authors $\quad 0270-6474 / 11 / 311688-05 \$ 15.00 / 0$
}

pocampal long-term potentiation (LTP) (Cullen et al., 1997; Lambert et al., 1998; Walsh et al., 2002; Wang et al., 2004; Townsend et al., 2006; Wei et al., 2010), a widely accepted cellular model of learning and memory (Bliss and Collingridge, 1993).

Tau protein may also play a crucial role in the cognitive decline in MCI and early AD. In the medial temporal lobe, the first area to be affected in AD, NFTs are elevated and their numbers in the hippocampal CA1 correlate with memory decline (Markesbery et al., 2006). Nevertheless, it has been suggested that tau intermediates are more important for the cognitive decline than the tangles themselves (Santacruz et al., 2005).

Thus, $\mathrm{A} \beta$ and tau are both fundamental in the early stages of $\mathrm{AD}$, but whether and how these two proteins interact is not yet established. Evidence for an important interaction includes the protection of tau-depleted neurons from $\mathrm{A} \beta$-induced neurodegeneration in culture (Rapoport et al., 2002). Moreover, the cognitive deficits that are seen in human amyloid precursor protein (hAPP)-overexpressing mice (Hsiao et al., 1996) are absent in hAPPoverexpressing mice with a genetic knock-out of tau protein (Roberson et al., 2007). Therefore, to further investigate a possible interaction between $\mathrm{A} \beta$ and tau and so help elucidate the mechanism underlying the cognitive decline in $\mathrm{MCI}$ and early $\mathrm{AD}$, we asked whether tau is required for the $\mathrm{A} \beta$-mediated impairment of LTP in the hippocampus, one of the earliest regions affected in $\mathrm{AD}$ (Braak and Braak, 1991). For this, we used both wild-type mice and mice with a genetic knock-out of tau protein ( $\mathrm{Tau}^{-1-}$ mice) (Dawson et al., 2001).

To investigate a possible molecular pathway for this interaction, we tested whether glycogen synthase kinase 3 (GSK-3) is involved in the $\mathrm{A} \beta$-induced impairment of LTP. GSK-3 is a serine/threonine kinase known to phosphorylate tau protein 
(Ishiguro et al., 1993) and to play a role in both synaptic plasticity (Hooper et al., 2007) and $\mathrm{A} \beta$-induced and tau-mediated neurodegeneration (Tackenberg and Brandt, 2009). If GSK-3 is involved in an interaction between $A \beta$ and tau, inhibition of GSK-3 could be a promising therapeutic strategy for MCI and early AD.

\section{Materials and Methods}

Mice. Animal care and experimental procedures were conducted in accordance with UK Home Office regulations under the Animals (Scientific Procedures) Act of 1986. Animals had access to food and water ad libitum. Holding facilities were maintained at a temperature of $\sim 22^{\circ} \mathrm{C}$, humidity of $60-70 \%$, and with a $12 \mathrm{~h} \mathrm{light/dark}$ cycle. We used 4- to 6-month-old $\mathrm{Tau}^{-1-}$ mice on a C57BL/6J background (Dawson et al., 2001) and age-matched C57BL/6J mice purchased from Charles River Laboratories. All mice were housed in the same animal facility under the same conditions for at least 2 weeks before experiments commenced. Mice of both sexes were used for the rodent $\mathrm{A} \beta$ experiment; for all other experiments only males were used.

Slice preparation. Parasagittal hippocampal slices $(400 \mu \mathrm{m})$ were prepared after decapitation under deep isoflurane-induced anesthesia. After dissection in ice-cold artificial CSF (ACSF) containing (in $\mathrm{mM}$ ) 126 $\mathrm{NaCl}, 3 \mathrm{KCl}, 1.25 \mathrm{NaH}_{2} \mathrm{PO}_{4}, 2 \mathrm{MgSO}_{4}, 2 \mathrm{CaCl}_{2}, 25 \mathrm{NaHCO}_{3}, 10$ glucose, $\mathrm{pH}$ 7.2-7.4, bubbled with carbogen gas $\left(95 \% \mathrm{O}_{2}, 5 \% \mathrm{CO}_{2}\right)$, slices were maintained at room temperature $\left(22-25^{\circ} \mathrm{C}\right)$ in a submerged-style holding chamber for at least $1 \mathrm{~h}$ and then incubated in drug/control solutions. For recording, slices were transferred to an interface-style recording chamber maintained at $33-35^{\circ} \mathrm{C}$ and superfused with ACSF at a rate of $2 \mathrm{ml} / \mathrm{min}$, and recording started at least $15 \mathrm{~min}$ after the slices were transferred.

Pharmacology. Rodent $\mathrm{A} \beta_{1-42}\left(\mathrm{rA} \beta_{1-42}\right)$ was dissolved in ACSF to a concentration of $10 \mu \mathrm{M}$ and frozen in aliquots. Single aliquots were defrosted and sonicated for $11 \mathrm{~min}$ before final dilution to $500 \mathrm{~nm}$ for slice incubation. Human $\mathrm{A} \beta_{1-42}\left(\mathrm{hA} \beta_{1-42}\right)$ was freshly prepared on the day of the experiment. It was initially dissolved in ACSF to a concentration of 5 $\mu \mathrm{M}$. Aliquots were then sonicated for $11 \mathrm{~min}$ before final dilution to 220 nM in ACSF.

Hippocampal slices were incubated in a submerged-style holding chamber in ACSF with or without $\mathrm{A} \beta_{1-42}$ or $\mathrm{A} \beta_{42-1}$ for 1-3 h before recording. Perfusion with a half-concentration of the drug continued after slices were transferred to the interface chamber.

AR-A014418 was dissolved in DMSO at $100 \mathrm{~mm}$ concentration and stored in frozen aliquots. For slice incubation, single aliquots of ARA014418 were defrosted and diluted to a final concentration of $1 \mu \mathrm{M}$ in ACSF. Slices were incubated for 30-45 min in AR-A014418 before the addition of $\mathrm{A} \beta_{1-42}$ or control ACSF.

To block $\mathrm{GABA}_{\mathrm{A}}$ receptor-mediated inhibition in some experiments, gabazine (SR 95531) was bath applied at $100 \mathrm{~nm}$ concentration to slices from which the CA3 had been removed.

$\mathrm{hA} \beta_{1-42}, \mathrm{hA} \beta_{42-1}, \mathrm{rA} \beta_{1-42}$, and gabazine were purchased from Tocris Bioscience; AR-A014418 was obtained from Sigma Aldrich.

Electrophysiological protocols. Extracellular field recordings from CA1 were made with an Axoclamp-2A amplifier in bridge mode, and data were acquired with an ITC-16 A/D board (Instrutech) using Igor Pro software (WaveMetrics). Borosilicate glass recording electrodes were filled with ACSF. Recording and stimulation electrodes were positioned in the stratum radiatum of CA1. Synaptic efficacy was monitored by stimulating the Schaffer collaterals at $0.2 \mathrm{~Hz}(50 \mu \mathrm{s}, 20-60 \mu \mathrm{A})$ with a monopolar tungsten electrode connected to a stimulus isolator unit (ISO-Flex, A.M.P.I.). Stimulation strength was set to elicit a field EPSP (fEPSP) of half-maximal amplitude. fEPSP slopes were monitored for a baseline period of at least $15 \mathrm{~min}$. If synaptic transmission was stable $(<$ $15 \%$ change in fEPSP slopes over $15 \mathrm{~min}$ ), a single high-frequency stimulus train was delivered $(100 \mathrm{~Hz}$ for $1 \mathrm{~s})$. To measure paired-pulse ratio both before and after LTP induction, two $50 \mu$ s pulses with an interpulse interval of $40 \mathrm{~ms}$ were given at a low stimulation strength.

Protein extraction and Western blot analysis. Slices were prepared as described above from wild-type and $\mathrm{Tau}^{-1-}$ mice and incubated in ACSF with or without $220 \mathrm{~nm} \mathrm{hA} \beta_{1-42}$ for $2 \mathrm{~h}$. A subset of slices was preincubated in $1 \mu \mathrm{M}$ AR-A014418 for $30 \mathrm{~min}$. The hippocampus was dissected from each slice and immediately frozen at $-80^{\circ} \mathrm{C}$. Total protein was extracted by homogenizing hippocampal slices in radioimmunoprecipitation assay buffer (Sigma Aldrich) supplemented with phosphatase inhibitors (PhosSTOP, Roche) and protease inhibitors (Complete Mini Protease Inhibitor Cocktail, Roche), followed by brief microcentrifugation. Protein concentrations were determined using the Bradford method. Two micrograms of total protein were separated on 3-8\% Tris acetate polyacrylamide gels (Invitrogen) and transferred to a polyvinylidene fluoride membrane. Membranes were blocked in phosphate buffered saline containing $0.1 \%$ Tween 20 and $10 \%$ milk and probed with primary antibody. Membranes were probed initially with an anti-phospho-tau primary antibody (AT8, 1:1000; Thermo Scientific) before stripping in Restore buffer (Pierce) and reprobing with a primary antibody to detect total tau (Tau5, 1:1000; Fitzgerald). Primary antibody binding was detected using an anti-mouse HRP-conjugated secondary antibody (Bio-Rad) and ECL Plus reagent (GE Healthcare) apposed to photographic film (CL-Xposure film, Thermo Scientific). Films were digitized and optical densities were determined using ImageJ (v1.43u; National Institutes of Health). To control for between-membrane variation, all samples from an individual mouse were run on a single gel, and optical densities were expressed as ratios of phospho/total tau normalized to the respective ACSF-only condition. Values presented are the mean of duplicate Western blots.

Data analysis. Changes in synaptic efficacy were estimated using the mean fEPSP slopes (measured from the middle third of the rising slope of the fEPSP) 30-45 min after high-frequency stimulation normalized to the mean fEPSP slope during the last 5 min of baseline recording. Pairedpulse ratio was expressed as the mean ratio of the amplitude of the second fEPSP to the amplitude of the first fEPSP (average of five paired pulses). Data were analyzed using Igor Pro, Matlab, and SPSS and are given as mean \pm SEM. Statistical significance was assessed using the Student's $t$ test or one-way ANOVA, followed by post hoc analysis with Bonferroni corrections when applicable. Unless otherwise stated, numbers $(N)$ refer to the number of slices obtained from at least six animals. Experiments in Figure 1 were performed blind such that the experimenter was not aware of genotype. In a subset (approximately half) of experiments in Figure 2, the experimenter was unaware of drug and genotype. As the average and variability of blind and nonblind experiments were similar, these data were pooled.

\section{Results}

\section{LTP in $\mathrm{A} \boldsymbol{\beta}_{1-42}$-exposed slices from $\mathrm{Tau}^{-/-}$mice}

First, we wanted to confirm that $\mathrm{A} \beta_{1-42}$ inhibits LTP in hippocampal slices from wild-type mice. We monitored fEPSPs evoked by extracellular stimulation of the Schaffer collateral pathway and induced LTP using high-frequency stimulation ( $100 \mathrm{~Hz}$ for $1 \mathrm{~s}$ ). In slices pretreated with $500 \mathrm{nM} \mathrm{rA} \beta_{1-42}$ for $1-3$ h, LTP was almost completely blocked (control: $153 \pm 12 \%, N=$ 19; $r A \beta_{1-42}: 112 \pm 11 \%, N=21$; $t$ test, $p<0.05$ ) (Fig. $1 a, c$ ). Similarly, hA $\beta_{1-42}$ also strongly impaired LTP (control: $137 \pm$ $5 \%, N=11$; hA $\beta_{1-42}: 115 \pm 5 \%, N=9$; $t$ test, $p<0.01$ ) (Fig. $2 a, c)$, consistent with previous reports (Walsh et al., 2002; Wang et al., 2004; Townsend et al., 2006). This was a specific effect of $\mathrm{hA} \beta_{1-42}$, because slices pretreated with a control peptide containing the hA $\beta$ peptide sequence in reverse order $\left(\mathrm{hA} \beta_{42-1}\right)$ showed a synaptic potentiation ( $137 \pm 7 \%, N=13$ ) (Fig. $2 a, c)$ equivalent to that in control slices ( $t$ test, $p=0.49$ ). These results demonstrate that, in wild-type mice, acute application of $A \beta_{1-42}$ impairs one or more of the cellular mechanisms necessary for LTP.

To investigate a possible interaction between $\mathrm{A} \beta$ and tau, we tested the effect of $\mathrm{A} \beta_{1-42}$ on LTP in $\mathrm{Tau}^{-/-}$mice (Dawson et al., 2001). Slices incubated in control solution showed normal levels of LTP and, remarkably, slices preincubated in $\mathrm{rA} \beta_{1-42}$ showed LTP of similar magnitude (control: $157 \pm 11 \%, N=11 ; \mathrm{rA} \beta_{1-42}$ : $145 \pm 12 \%, N=15$; $t$ test, $p=0.51$ ) (Fig. $1 b, c$ ). Equivalent results were obtained using hA $\beta_{1-42}$ (control: $138 \pm 5 \%, N=15$; hA $\beta_{1-42}$ : 
$138 \pm 7 \%, N=9 ; t$ test, $p=0.48$ ) (Fig. $2 b, c)$. Univariate ANOVA revealed a main effect of treatment, as well as a genotypetreatment interaction for both rodent and human $\mathrm{A} \beta_{1-42}\left(\mathrm{rA} \beta_{1-42}: F_{(1,65)}=3.23\right.$, $p<0.05 ; \mathrm{hA} \beta_{1-42}: F_{(1,40)}=5.03, p<$ $0.05)$, resulting from a significant effect of $\mathrm{A} \beta$ in wild-type slices.

To investigate whether this result could be caused by different basic synaptic properties between wild-type and $\mathrm{Tau}^{-1-}$ mice, we measured the synaptic input-output relationship and paired-pulse ratio (PPR). We found no difference in synaptic input-output relationships between wild-type and $\mathrm{Tau}^{-1-}$ mice, indicating equivalent basal synaptic transmission (supplemental Fig. 1a, available at www.jneurosci.org as supplemental material). Moreover, we observed no difference in the PPR (supplemental Fig. $1 b$ ) between wild-type and $\mathrm{Tau}^{-1-}$ mice [wild-type PPR before LTP: $1.67 \pm 0.05$, PPR after LTP: $1.68 \pm$ 0.10, $N=12$; $\mathrm{Tau}^{-1-}$ PPR before LTP: $1.63 \pm 0.11$, PPR after LTP: $1.72 \pm 0.06$, $N=10$; repeated measures ANOVA revealed no effect of genotype (betweensubjects factor $\left.F_{(1,17)}=0.323 ; p=0.58\right)$ on PP value before or after LTP induction (within-subjects factor $F_{(1,17)}=0.55 ; p=$ 0.47] (supplemental Figure 1). There was also no significant difference in post-tetanic potentiation (PTP) between wild-type and Tau $^{-1-}$ mice (wild-type PTP: $193 \pm 9 \%$, $N=28$ mice, Tau $^{-l-}$ PTP: $211 \pm 10 \%$, $N=18$ mice, $t$ test $p=0.18$ ) (Fig. $1 a, b$, $2 a, b)$. To confirm that the LTP results were not caused by differences in GABAergic inhibition, experiments were repeated with equivalent results in the presence of $100 \mathrm{~nm}$ gabazine in slices with the CA3 removed (supplemental Fig. 2, available at www.jneurosci.org as supplemental material). Altogether, these results suggest that differences in basic synaptic properties are unlikely to account for the lack of A $\beta_{1-42}$-induced impairment of LTP in $\mathrm{Tau}^{-/-}$mice.

Given that NFTs comprising hyperphosphorylated tau are a prominent $\mathrm{AD}$ pathology alongside $\mathrm{A} \beta$ plaques, we asked whether the $\mathrm{A} \beta_{1-42}$-induced impairment of LTP is associated with tau phosphorylation and requires activity of GSK-3, a serine/threonine kinase known to phosphorylate tau protein (Ishiguro et al., 1993). We used AR-A014418, which is a highly specific GSK-3 inhibitor that does not significantly inhibit closely related kinases such as cdk2 or cdk5 (Bhat et al., 2003). First, to test whether $\mathrm{hA} \beta_{1-42}$ increases tau phosphorylation and ARA014418 inhibits tau phosphorylation under our experimental conditions, we used Western blot analysis of hippocampal tissue from slices incubated in ACSF with or without $220 \mathrm{nM} \mathrm{hA} \beta_{1-42}$. In a subset of experiments, slices were preincubated in $1 \mu \mathrm{M}$ AR-A014418 to inhibit GSK-3 activity. A significant effect of treatment on the ratio of phosphorylated tau to total tau was found (ANOVA, $\left.F_{(2,22)}=3.99 p<0.05\right)$ (Fig. 3). Incubation with
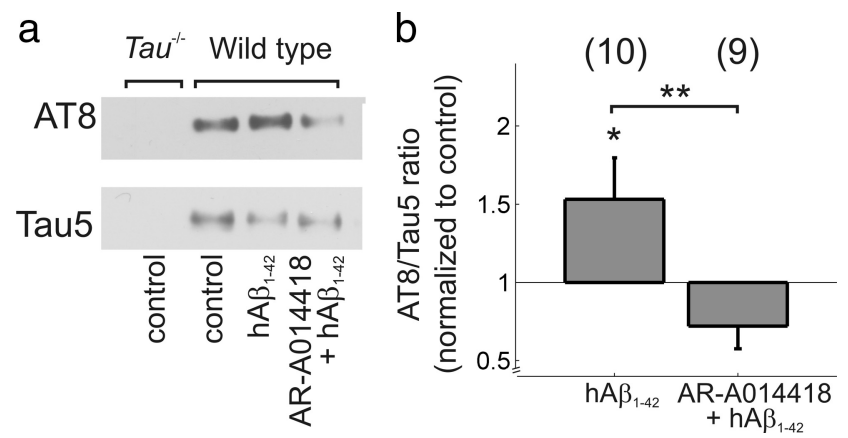

Figure 3. A specific inhibitor of GSK-3 reduces $A \beta_{1-42}$-induced phosphorylation of tau. $\boldsymbol{a}$, Example Western blot showing immunoreactivity to Tau5 (total Tau) and AT8 (phosphorylated Tau). $\boldsymbol{b}$, Pooled data for AT8/Tau 5 ratios normalized to immunoreactivity observed in control conditions in each mouse; ${ }^{*} p<0.05 ;{ }^{* *} p<0.01$. The numbers of mice are shown in parentheses. 
a

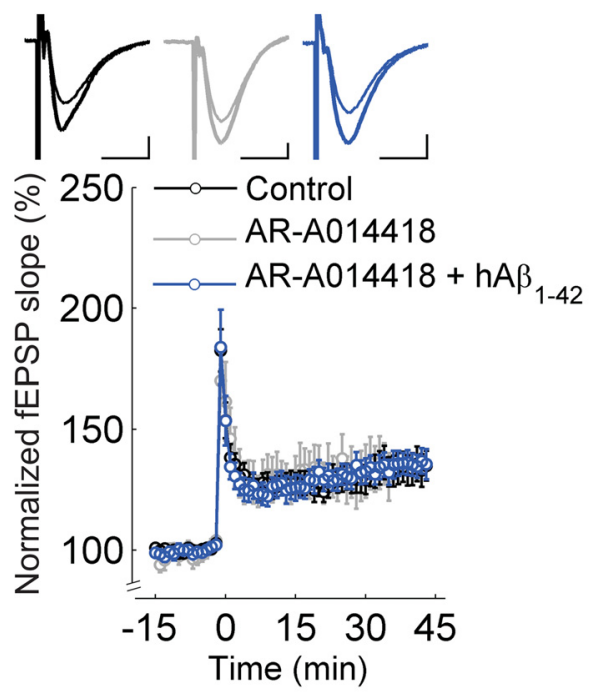

b

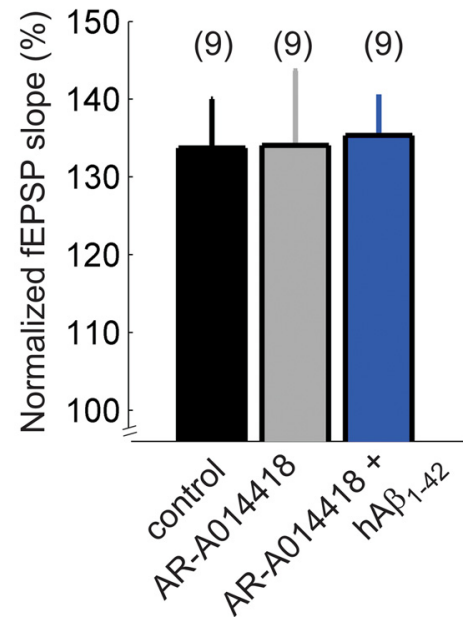

Figure 4. The specific GSK-3 inhibitor AR-A014418 prevents impairment of LTP by human A $\beta_{1-42}$ in wild-type slices. $\boldsymbol{a}$ Hippocampal Schaffer collateral-CA1 LTP in wild-type mice in control ACSF (black) or after incubation with AR-A014418 alone (gray) or AR-A014418 followed by incubation with $\mathrm{hA} \beta_{1-42}$ (blue). The insets show superimposed example traces before and 35 min after high-frequency stimulation for each condition. Scale bars: $5 \mathrm{~ms}, 200 \mu \mathrm{V}$. $\boldsymbol{b}$, Summary of results $30-35 \mathrm{~min}$ after high-frequency stimulation. Error bars are SEM. The numbers of slices are shown in parentheses.

$\mathrm{hA} \beta_{1-42}$ significantly increased tau phosphorylation in hippocampal tissue compared with control slices (AT8/Tau5 ratio $=1.53 \pm$ $0.26, N=10$, one-sample $t$ test, $p<0.05$ ), and the phosphorylation ratio in slices preincubated with AR-A014418 was significantly lower than those incubated with hA $\beta_{1-42}$ alone (AT8/Tau5 ratio $=0.72 \pm$ $0.14, N=9$, two-sample $t$ test, $p<0.01$ ). Slices exposed to $1 \mu \mathrm{M}$ AR-A014418 alone showed tau phosphorylation equivalent to that observed in control conditions (AT8/Tau5 ratio $=0.96 \pm 0.16, N=$ 4). Next, we tested whether this concentration of AR-A014418 could block the hA $\beta_{1-42}$-induced impairment of LTP. When hippocampal slices from wild-type mice were pre-exposed to $1 \mu \mathrm{M}$ AR-A014418 for $30 \mathrm{~min}$ before incubation with $\mathrm{hA} \beta_{1-42}$, we observed LTP of a magnitude equivalent to that in control slices (control: $134 \pm 6 \%$, $N=9$, hA $\beta_{1-42}: 135 \pm 5 \%, N=9, t$ test $\left.p=0.58\right)($ Fig. $4 a, b)$ and in slices exposed to AR-A014418 alone $(134 \pm 6 \%, N=9, t$ test $p=$ 0.51 , compared with control) (Fig. $4 a, b)$. This recovery of LTP was attributable to AR-A014418, since LTP was not observed in slices pre-exposed to vehicle ( $0.01 \%$ DMSO) for 30 min before incubation with hA $\beta_{1-42}$ (supplemental Fig. 3a,b), and vehicle alone did not affect LTP (supplemental Fig. 3a,b). The finding that AR-A014418 completely blocked the hA $\beta_{1-42}$-induced, augmented tau phosphorylation, as well as impairment of LTP, suggests that activation of GSK-3 and its phosphorylation of tau are required for the effect of $\mathrm{A} \beta_{1-42}$ on synaptic plasticity.

\section{Discussion}

Two principal findings emerge from this work. First, in $\mathrm{Tau}^{-/-}$ mice, neither the rodent nor human version of $\mathrm{A} \beta_{1-42}$ impaired hippocampal LTP, in contrast to the robust impairment of LTP they caused in slices from wild-type mice. Second, a specific inhibitor of the tau kinase GSK-3 prevented both the augmented tau phosphorylation and the impairment of LTP that were otherwise seen following $\mathrm{A} \beta_{1-42}$ treatment in wild-type mice.

Because cognitive decline in early $\mathrm{AD}$ is associated with pathology in the medial temporal lobe (Braak and Braak, 1991), we

investigated LTP at the hippocampal CA3-CA1 synapse, a widely accepted cellular model for learning and memory. Our confirmation that $A \beta_{1-42}$ impaired LTP in slices from wild-type mice is in agreement with a wealth of previous reports (Cullen et al., 1997; Lambert et al., 1998; Chen et al., 2002; Walsh et al., 2002; Wang et al., 2004; Townsend et al., 2006) showing that soluble $\mathrm{A} \beta$ oligomers have an inhibitory effect on LTP. It also suggests that, under our experimental conditions, $A \beta$ assembled into the oligomeric complexes thought to be the synaptotoxic form of the peptide. We show that the magnitude of LTP is not reduced in slices from $\mathrm{Tau}^{-1-}$ mice exposed to either human or rodent $A \beta_{1-42}$. This suggests that tau protein is one element required for the synaptotoxic effects of $\mathrm{A} \beta_{1-42}$, consistent with the finding that tau-depleted neurons do not degenerate in the presence of A $\beta$ (Rapoport et al., 2002). The similar synaptic input-output relationships and unchanged paired-pulse ratios with LTP in wild-type and $\mathrm{Tau}^{-1-}$ mice that we observed suggests that this result is not caused by different presynaptic properties in $\mathrm{Tau}^{-1-}$ mice, but that the absence of tau uncouples $A \beta$ from its downstream effects that impair the postsynaptic mechanisms required for LTP. In support of this postsynaptic interpretation, a dendritic role for tau in mediating $\mathrm{A} \beta$ toxicity was recently reported (Ittner et al., 2010). Nevertheless, this does not exclude a contribution of presynaptic mechanisms; for example, $\mathrm{A} \beta$-induced deficits in axonal transport are prevented in $\mathrm{Tau}^{-1-}$ neurons (Vossel et al., 2010).

It is a priority to establish which molecular pathways underlie the $\mathrm{A} \beta_{1-42}$-induced impairment of LTP. We found that the specific GSK-3 inhibitor AR-A014418 can prevent impairment of LTP by hA $\beta_{1-42}$ in wild-type slices. This suggests that GSK-3, via its subsequent phosphorylation of tau (Ishiguro et al., 1993), is a key component in the pathway by which $\mathrm{A} \beta$ exerts its pathogenic downstream effects on LTP, similar to $A \beta$-mediated neurodegeneration (Tackenberg and Brandt, 2009). In support of this, we demonstrate that inhibition of GSK-3 prevents the augmented tau phosphorylation seen following incubation in $\mathrm{A} \beta$ alone. However, while our results show that $A \beta$-induced impairment of LTP is associated with increased levels of tau phosphorylation and that a specific inhibitor of GSK-3 blocks both increased phosphorylation and impairment of LTP, they do not provide conclusive evidence that phosphorylated tau protein mediates this impairment. The results also do not exclude the involvement of other kinases previously implicated in the $\mathrm{A} \beta$-induced impairment of LTP, including c-Jun $N$-terminal kinase, cdk5, p38 mitogen-activated protein kinase (Wang et al., 2004), and protein kinase A (Vitolo et al., 2002). Nevertheless, the complete recovery of LTP magnitude in the presence of AR-A014418 is striking.

Previous studies have shown a correlation between behavior and synaptic plasticity, with both learning and LTP being impaired in the same animal model of AD (Chapman et al., 1999; Stéphan et al., 2001). Combined with the behavioral findings of Roberson et al. (2007), the present data are the first to link LTP 
and behavior through tau protein. This both strengthens the link between synaptic plasticity and memory and suggests a mechanism underlying the cognitive dysfunction in early AD. Nevertheless, our data were obtained with acute application of synthetic $\mathrm{A} \beta$ peptides, whereas the lack of cognitive deficits was found in hAPP-overexpressing and tau knock-out mice (Roberson et al., 2007); there may be subtle differences between chronic in vivo and acute in vitro exposure. For example, 1-2 d APP overexpression or $A \beta$ exposure can reduce spine density, whereas $1 \mathrm{~h}$ exposure to $\mathrm{A} \beta$ peptides alters the structural plasticity of individual spines (Wei et al., 2010).

Overall, the findings presented here indicate that the absence of tau prevents the synaptic dysfunction induced by $\mathrm{A} \beta_{1-42}$, and support previous suggestions that tau acts downstream of $A \beta$ (Hardy and Selkoe, 2002), although parallel pathways remain possible (Small and Duff, 2008). These results, using acute exposure to soluble $\mathrm{A} \beta_{1-42}$, may be relevant to early $\mathrm{AD}$, when synaptic dysfunction is present but before extensive plaque formation has occurred. However, later in the disease process the absence of functional tau protein may render the brain more vulnerable to $\mathrm{A} \beta$ (Dawson et al., 2010). Nevertheless, the molecular cascades being uncovered suggest that GSK-3 might be a potential drug target for treating synaptic dysfunction and, hence, improving cognitive function during early $\mathrm{AD}$.

\section{References}

Bhat R, Xue Y, Berg S, Hellberg S, Ormö M, Nilsson Y, Radesäter AC, Jerning E, Markgren PO, Borgegård T, Nylöf M, Giménez-Cassina A, Hernández F, Lucas JJ, Díaz-Nido J, Avila J (2003) Structural insights and biological effects of glycogen synthase kinase 3-specific inhibitor AR-A014418. J Biol Chem 278:45937-45945.

Bliss TV, Collingridge GL (1993) A synaptic model of memory: long-term potentiation in the hippocampus. Nature 361:31-39.

Braak H, Braak E (1991) Neuropathological stageing of Alzheimer-related changes. Acta Neuropathol 82:239-259.

Chapman PF, White GL, Jones MW, Cooper-Blacketer D, Marshall VJ, Irizarry M, Younkin L, Good MA, Bliss TV, Hyman BT, Younkin SG, Hsiao KK (1999) Impaired synaptic plasticity and learning in aged amyloid precursor protein transgenic mice. Nat Neurosci 2:271-276.

Chen QS, Wei WZ, Shimahara T, Xie CW (2002) Alzheimer amyloid betapeptide inhibits the late phase of long-term potentiation through calcineurin-dependent mechanisms in the hippocampal dentate gyrus. Neurobiol Learn Mem 77:354-371.

Cullen WK, Suh YH, Anwyl R, Rowan MJ (1997) Block of LTP in rat hippocampus in vivo by $\beta$-amyloid precursor protein fragments. Neuroreport 8:3213-3217.

Dawson HN, Ferreira A, Eyster MV, Ghoshal N, Binder LI, Vitek MP (2001) Inhibition of neuronal maturation in primary hippocampal neurons from tau deficient mice. J Cell Sci 114:1179-1187.

Dawson HN, Cantillana V, Jansen M, Wang H, Vitek MP, Wilcock DM, Lynch JR, Laskowitz DT (2010) Loss of tau elicits axonal degeneration in a mouse model of Alzheimer's disease. Neuroscience 169:516-531.

Hardy J, Selkoe DJ (2002) The amyloid hypothesis of Alzheimer's disease: progress and problems on the road to therapeutics. Science 297:353-356.

Hooper C, Markevich V, Plattner F, Killick R, Schofield E, Engel T, Hernandez F, Anderton B, Rosenblum K, Bliss T, Cooke SF, Avila J, Lucas JJ, Giese KP, Stephenson J, Lovestone S (2007) Glycogen synthase kinase-3 inhibition is integral to long-term potentiation. Eur J Neurosci 25:81-86.

Hsiao K, Chapman P, Nilsen S, Eckman C, Harigaya Y, Younkin S, Yang F, Cole G (1996) Correlative memory deficits, $A \beta$ elevation, and amyloid plaques in transgenic mice. Science 274:99-102.

Ishiguro K, Shiratsuchi A, Sato S, Omori A, Arioka M, Kobayashi S, Uchida T,
Imahori K (1993) Glycogen synthase kinase 3- $\beta$ is identical to tau protein kinase I generating several epitopes of paired helical filaments. FEBS Lett 325:167-172.

Ittner LM, Ke YD, Delerue F, Bi M, Gladbach A, van Eersel J, Wölfing H, Chieng BC, Christie MJ, Napier IA, Eckert A, Staufenbiel M, Hardeman E, Götz J (2010) Dendritic function of tau mediates amyloid- $\beta$ toxicity in Alzheimer's disease mouse models. Cell 142:387-397.

Lambert MP, Barlow AK, Chromy BA, Edwards C, Freed R, Liosatos M, Morgan TE, Rozovsky I, Trommer B, Viola KL, Wals P, Zhang C, Finch CE, Krafft GA, Klein WL (1998) Diffusible, nonfibrillar ligands derived from $A \beta 1-42$ are potent central nervous system neurotoxins. Proc Natl Acad Sci U S A 95:6448-6453.

Lue LF, Kuo YM, Roher AE, Brachova L, Shen Y, Sue L, Beach T, Kurth JH, Rydel RE, Rogers J (1999) Soluble amyloid $\beta$ peptide concentration as a predictor of synaptic change in Alzheimer's disease. Am J Path 155:853-862.

Markesbery MR, Schmitt FA, Kryscio RJ, Davis DG, Smith CD, Wekstein DR (2006) Neuropathologic substrate of mild cognitive impairment. Arch Neurol 63:38-46.

Rapoport M, Dawson HN, Binder LI, Vitek MP, Ferreira A (2002) Tau is essential to $\beta$-amyloid-induced neurotoxicity. Proc Natl Acad Sci U S A 99:6364-6369.

Roberson ED, Scearce-Levie K, Palop JJ, Yan F, Cheng IH, Wu T, Gerstein H, Yu GQ, Mucke L (2007) Reducing endogenous tau ameliorates amyloid $\beta$-induced deficits in an Alzheimer's disease mouse model. Science 316:750-754.

Santacruz K, Lewis J, Spires T, Paulson J, Kotilinek L, Ingelsson M, Guimaraes A, DeTure M, Ramsden M, McGowan E, Forster C, Yue M, Orne J, Janus C, Mariash A, Kuskowski M, Hyman B, Hutton M, Ashe KH (2005) Tau suppression in a neurodegenerative mouse model improves memory function. Science 309:476-481.

Selkoe DJ (2002) Alzheimer's disease is a synaptic failure. Science 298:789-791

Small SA, Duff K (2008) Linking A $\beta$ and tau in late-onset Alzheimer's disease: a dual pathway hypothesis. Neuron 60:534-542.

Stéphan A, Laroche S, Davis S (2001) Generation of aggregated $\beta$-amyloid in the rat hippocampus impairs synaptic transmission and plasticity and causes memory deficits. J Neurosci 21:5703-5714.

Tackenberg C, Brandt R (2009) Divergent pathways mediate spine alterations and cell death induced by amyloid- $\beta$, wild-type tau, and R406W tau. J Neurosci 29:14439-14450.

Townsend M, Shankar GM, Mehta T, Walsh DM, Selkoe DJ (2006) Effects of secreted oligomers of amyloid $\beta$-protein on hippocampal synaptic plasticity: a potent role for trimers. J Physiol 572:477-492.

Vitolo OV, Sant'Angelo A, Costanzo V, Battaglia F, Arancio O, Shelanski M (2002) Amyloid $\beta$-peptide inhibition of the PKA/CREB pathway and long-term potentiation: reversibility by drugs that enhance cAMP signaling. Proc Natl Acad Sci U S A 99:13217-13221.

Vossel KA, Zhang K, Brodbeck J, Daub AC, Sharma P, Finkbeiner S, Cui B, Mucke L (2010) Tau reduction prevents $A \beta$-induced defects in axonal transport. Science 330:198.

Walsh DM, Klyubin I, Fadeeva JV, Cullen WK, Anwyl R, Wolfe MS, Rowan MJ, Selkoe DJ (2002) Naturally secreted oligomers of amyloid $\beta$ protein potently inhibit hippocampal long-term potentiation in vivo. Nature 416:535-539.

Wang Q, Walsh DM, Rowan MJ, Selkoe DJ, Anwyl R (2004) Block of longterm potentiation by naturally secreted and synthetic amyloid $\beta$-peptide in hippocampal slices is mediated via activation of the kinases c-Jun $N$-terminal kinase, cyclin-dependent kinase 5, and p38 mitogen-activated protein kinase as well as metabotropic glutamate receptor type 5 . J Neurosci 24:3370-3378.

Wei W, Nguyen LN, Kessels HW, Hagiwara H, Sisodia S, Malinow R (2010) Amyloid $\beta$ from axons and dendrites reduces local spine number and plasticity. Nat Neurosci 13:190-196. 